\title{
Value Addition to Forecasting: Towards Kharif Rice Crop Predictability Through Local Climate Variations Associated With Indo-Pacific Climate Drivers.
}

Hemadri Bhusan Amat ( $\sim$ hbamat@uohyd.ac.in )

University of Hyderabad https://orcid.org/0000-0003-4077-744X

\section{Maheswar Pradhan}

Indian Institute of Tropical Meteorology

C. T. Tejavath

Indian Institute of Tropical Meteorology

Avijit Dey

Indian Institute of Tropical Meteorology

Suryachandra A. Rao

Indian Institute of Tropical Meteorology

\section{A. K. Sahai}

Indian Institute of Tropical Meteorology

Karumuri Ashok

University of Hyderabad

\section{Original Paper}

Keywords: Indian Institute of Tropical Meteorology (IITM), IITM-CFS, Indo-Pacific drivers

Posted Date: February 9th, 2021

DOl: https://doi.org/10.21203/rs.3.rs-169288/v1

License: (c) (i) This work is licensed under a Creative Commons Attribution 4.0 International License.

Read Full License

Version of Record: A version of this preprint was published at Theoretical and Applied Climatology on March 8th, 2021. See the published version at https://doi.org/10.1007/s00704-021-03572-6. 


\section{Abstract}

The Indian Institute of Tropical Meteorology (IITM) has generated seasonal and extended range hindcast products for 1981-2008 and 2003-2016 respectively using the IITM-Climate Forecast System (IITM-CFS) coupled model at various resolutions and configurations. Notably, our observational analysis suggests that for the 1981-2008 period, the tropical Indo-Pacific drivers, namely, the canonical El Niño-Southern Oscillation (ENSO), ENSO Modoki, and Indian Ocean Dipole (IOD) are significantly associated with the observed Kharif rice production (KRP) of various rice-growing Indian states. In this paper, using the available hindcasts, we evaluate whether these state-of-the-art retrospective forecasts capture the relationship of the KRP of multiple states with the local rainfall as well as the tropical Indo-Pacific drivers, namely, the canonical ENSO, ENSO Modoki and the IOD. Using techniques of anomaly correlation, partial correlation, and pattern correlation, we surmise that the IITM-CFS successfully simulate the observed association of the tropical Indo-Pacific drivers with the local rainfall of many states during the summer monsoon. Significantly, the observed relationship of the local KRP with various climate drivers is predicted well for several Indian states such as United Andhra Pradesh, Karnataka, Odisha, and Bihar. The basis seems to be the model's ability to capture the teleconnections from the tropical Indo-Pacific drivers such as the IOD, canonical and Modoki ENSOs to the local climate, and consequently, the Kharif rice production.

\section{Introduction}

The importance of the Indian summer monsoon rainfall (ISMR), which spans from June through September (JJAS), for the growth of the Indian agro-economy, is well-known (Gadgil et al., 2006). A reasonably skilled long-lead prediction of ISMR at regional and local scales in India would be immensely useful to the Indian farmer community as well as policymakers in planning the agricultural practices in advance, crop management \& food security/decision-making. However, successful dynamical prediction of Indian summer monsoon on extended and seasonal time scales has not been feasible till a decade back owing to the limitations in model fidelity in the simulation of the intraseasonal and interannual variability, owing to factors such as coarse model resolution, and lack of necessary observational data for the necessary data assimilation. In this context, the Ministry of Earth Sciences (MoES), Government of India, launched the Monsoon Mission Project in 2012 to develop dynamical models from weather through seasonal scale prediction of the ISMR (Rao et al., 2019). The National Centers for Environmental Prediction (NCEP) based Climate Forecast System version 2 (CFSv2), a state-of-the-art OceanAtmospheric coupled model, has been chosen as the basic model, on which scientists in India as well as abroad have worked intending to improve the extended and seasonal monsoon prediction. The efforts have been successful, and the retrospective forecasts on different timescales have been shown to be skilful, and some of the products operational as well, e.g. the applications in the forecast of long-range monsoon outlook, monsoon onset, intraseasonal monsoon oscillation, monsoon active-break spells, extreme events like heat and cold waves etc. (Sahai et al., 2016; Pai et al., 2017, Pradhan et al., 2017; Chattopadhyay et al., 2018, 2019; Pattanaik et al., 2019). 
The CFSv2 retrospective seasonal forecasts are a set of 9-month long hindcasts initiated on every $5^{\text {th }}$ day of the month with four cycles per day (i.e. 00, 06, 12, $18 \mathrm{GMT}$ ), starting from $1^{\text {st }}$, from the period of 1981 2008. Initial conditions for the ocean and atmospheric component come from the NCEP Climate Forecast System Reanalysis (CFSR) (Saha et al., 2010). An Ensemble prediction system (EPS) has been used to generate numerous forecasts of ISMR in an extended range scale from different initial conditions using the CFSv2 model. The extended range prediction (ERP) refers to a meteorological forecast of more than 10-20 days in advance. The EPS generates many forecasts from different initial conditions, and the ensemble forecast could be informed to the user community as an end product, in term of probability. Such estimations of uncertainties will add more decision-making capabilities to the user community in a practical sense. The importance of ERP has been used for determining the Monsoon Intraseasonal Oscillations (MISOs) (Sahai et al., 2013a; Sharmila et al., 2013) in term of active \& break spells, which could be a crucial factor for farmers for agricultural scheduling. So, these lead seasonal and extended range monsoon rainfall prediction skills motivate us to make an attempt to explore the usefulness of the climate prediction skills for the Kharif rice production forecast. Indeed, the all India crop production is significantly correlated with the ISMR (e.g. Gadgil 2006; Krishna Kumar et al., 2004; V. Prasanna, 2014; Amat and Ashok, 2018), i.e. the crops are grown during both the monsoon \& the post-monsoon season are highly influenced by the ISMR.

The rationale for considering the dynamical forecast, despite a challenge that the local rainfall may not be predicted with very high skill, comes from the fact that the current day climate models successfully predict the tropical ocean drivers such as the El Niño Southern Oscillation (ENSO), which are instrumental in affecting the global climate variability, with excellent lead skills (e.g. Jeong et al., 2012, Srivastava et al., 2015). Indeed, the ENSO is known to influence the ISMR variability (Sikka and Gadgil, 1980; Keshavamurty, 1982; Palmer et al.,1992; Shukla and Paolina, 1983; Navarra et al.,1999; Ju and Slingo, 1995; Soman and Slingo, 1997; Dai and Wigley, 2000; Ashok et al., 2004, Ashok et al., 2019). In a linear sense, stronger El Niños are linked with a drier condition over the Indian region. The El Niño Modoki events, the other type of El Niños, have shown an increase in frequency after the mid-1970s (Ashok et al. 2007; Kao and Yu 2009; Kug et al. 2009; Marathe et al. 2015; Jadhav et al., 2015), and are also associated with the anomalously drier condition over the Indian region (Kumar et al., 2006; Weng et al., 2007 Ratnam et al., 2010), particularly the peninsular region (Ashok et al., 2007, 2009, 2019). Other than the El Niño \& El Niño Modoki, strong Indian Ocean Dipole (IOD) (Saji et al. 1999; Webster et al. 1999; Murtugudde et al., 2000), also plays a major role on the ISMR variability (Ashok et al. 2004; Ashok and Saji 2007; Varikoden and Preethi, 2013; Krishnaswamy et al., 2015). Several IOD events are known to occur simultaneously with El Niños, owing to their seasonal phase locking characteristics (e.g. Yamagata et al., BAMS, 2003, Saji et al., 1999, Saji 2018). Strong positive IOD events co-occurring with an El Niño, such as in 1997, reduce the anomalously negative ISMR induced by a co-occurring the El Niño (e.g. Ashok et al., 2001). Given all this, the variability of the tropical Indo-pacific drivers is obviously important for local crop production in many regions of India. In fact, Amat and Ashok (2018) show that the Kharif rice production in various states is statistically significantly correlated with one or more of the tropical Indopacific drivers. 
In this study, we explore whether the extended-range and seasonal climate prediction skills of the IITMCFS hindcast data-sets can translate into tenable lead forecasts skills for the observed Kharif rice production (KRP) in the various Indian states. The states considered are West Bengal (WB), Haryana, Kerala, Bihar, Punjab, Uttar Pradesh (UP), Madhya Pradesh (MP), United Andhra Pradesh (UAP), Karnataka and Odisha. We structure this paper as follows. In the next section (Section 2), we introduce the details of various data-sets used and the methodology of our analysis. We present our results in Section 3 and our conclusions in Section 4.

\section{Data And Methodology}

We use the CFSv2 seasonal hindcast rainfall \& Sea Surface Temperature (SST) at the T382 horizontal atmospheric resolution ( 38 km), generated from 1981 to 2008 (Ramu et al., 2016). The data-set comprises of seasonal hindcast simulations for the March, April and May initial conditions with 12 lagged ensemble members during this period. The initial conditions are obtained from the NCEP Climate Forecast System Reanalysis (CFSR) (Saha et al., 2010). The present study uses the latest version of the NCEP CFSv2 (Saha et al. 2013) model. For extended range predictions, the coupled model (CFS) is run at two horizontal resolution T126 $(\sim 100 \mathrm{~km})$ and T382 $(\sim 38 \mathrm{~km})$ with 64 vertical levels. The model, initialized every Wednesday, is run for the next 32 days. Four ensemble members each from CFST126 and CFST382 are run routinely. In the case of each model, a Single forecast was obtained by averaging of four ensemble members. The ensembles have been designed by a perturbation technique, as described in Abhilash et al., (2014). In this study, the available extended range hindcast data-sets generated with T382 resolution for the 2003-2016(excluding 2010) period have been utilized. The model variables are extracted at $1^{0} \times 1^{0}$ horizontal resolutions for comparison with the observations. The Week one lead forecast (denoted as W01) was prepared by averaging daily hindcasts for each day of week 1 (henceforth, W01). For example, based on the initial conditions (IC) of 31st May, we have generated the $1^{\text {st }}-7^{\text {th }}$ June data, based on $7^{\text {th }}$ June IC we have collected $8^{\text {th }}-14^{\text {th }}$ June data, and so on. The similar, procedure was adopted for Weeks 2, 3 and 4 (denoted as W02, W03, and W04, respectively). Further details can be obtained from Abhilash et al. (2014).

This extended-range data was originally meant to provide forecast up to 4-week lead and evaluate the weekly skill. This is routinely done by taking the seven-day average for the given 18 weeks from 1 st June to 4th October. But, as we consider the annual agriculture production, the relevance of the weekly forecasts cannot be easily estimated. In other words, we are interested in the estimation of the relevance of these weekly hindcasts from monthly to seasonal scales. We reconstructed the seasonal data from these individual week forecasts (W01, W02, W03, W04) for June through September (JJAS), as briefly described in the following. At first, we calculate for each individual year from 2003 through 2016 (or to be more specific each summer monsoon), the weekly mean of hindcast rainfall, etc., for each of the 18 weeks, at W01, W02, W03 \& W04 lead. Then, we examine the skills of these hindcasts by comparing with 18 weeks from observation. Then, we calculate the correlations and partial correlations between the seasonal agriculture productions and the tropical Indo-Pacific climate driver indices. India Meteorological 
Department (IMD) 's high resolution $\left(0.25 \square \times 0.25^{\square}\right)$ gridded rainfall data-set (Pai et al.,2014) over India available from 1901-2018 and The Hadley Centre Global Sea Ice and Sea Surface Temperature (HadlSST) (Rayner et al.,2003), available from 1871-2018, have been used as the observed data-sets. The state-wise Kharif rice production data-set, available from the Directorate of Economics and Statistics (DES), Ministry of Agriculture, Government of India, for the period of 1981-2014, are also analyzed in the study.

The current study addresses two objectives. The first one is to ascertain how skilful the IITM CFS extended and seasonal hindcasts are in reproducing the observed association of the local KRP with local rainfall. Going further, the local rainfall variations are often dependent on the variations of the tropical Indo-pacific climate drivers such as the ENSO, ENSO Modoki and IOD. Consequently, the observed KRP also has a significant association with the variability of these climate drivers (e.g., Amat et al., 2018). In this context, our second objective is to examine the fidelity of the association of the hindcast variability of these tropical Indo-pacific climate drivers with the observed local KRP. This is achieved by (a) computing the partial correlations of the observed local KRP with model-predicted NINO3, EMI and IODMI, and (b) comparing these with the corresponding partial correlations from the observations.

For determining the statistical significance of the correlation analysis, we used the one-tailed Student's ttest, where the degree of freedom ( $d f$ ) has been taken as the limited number of years available. We use the pattern correlation, which is the linear correlation between the spatially distributed values of a particular parameter with another such parameter over the same domain; for example, the gridded JJAS 2009 rainfall observations and corresponding model predictions over the Indian subcontinent. This is a diagnostic estimate that quantifies the model's skill in predicting the particular variable over a designated domain at a single time point/stratum from the context of model evaluation. We also carry out the composite plot analysis to see the impact of the tropical Indo-Pacific drivers on the ISMR at a different period during 2003-2016.

Further, the partial correlation method (Nicholls; 1983) has been used to linearly isolate the individual impacts of multiple co-occurring the prominent tropical Indo-Pacific climate drivers during the JJAS season, specifically, the ENSO, ENSO Modoki and IOD (e.g. Ashok et al. 2001, 2007; Ashok and Saji 2007; Guan et al. 2003a; Behera et al. 2005).

The relevant indices used in our analysis are:

- NINO3- Area-averaged sea surface temperature anomaly (SSTA) of the region bounded by $\left(5^{\circ} \mathrm{N}-\right.$ $5^{\circ} \mathrm{S}, 150^{\circ} \mathrm{W}-90^{\circ} \mathrm{W}$ ) (Trenberth, 1997), which represents the variability of the canonical ENSO.

- Indian Ocean Dipole Mode Index (IODMI) - Area-averaged SSTA difference between the western box $\left(50^{\circ} \mathrm{E}-70^{\circ} \mathrm{E}, 10^{\circ} \mathrm{S}-10^{\circ} \mathrm{N}\right)$ and the eastern box $\left(90^{\circ} \mathrm{E}-110^{\circ} \mathrm{E}, 10^{\circ} \mathrm{S}\right.$ to the equator) (Saji et al., 1999).

- ENSO Modoki (EMI)- It is defined, following Ashok et al., (2007), as

- $E M I=[S S T A]_{A}-0.5 *[S S T A]_{B}-0.5 *[S S T A]_{C}$ 
where $[S S T A]_{A}=$ the area-averaged SSTA bounded by the region $A\left(165^{\circ} \mathrm{E}-140^{\circ} \mathrm{W}, 10^{\circ} \mathrm{S}-10^{\circ} \mathrm{N}\right),[\mathrm{SSTA}]_{B}=$ the area-averaged SSTA bounded by the region $B\left(110^{\circ} \mathrm{W}-70^{\circ} \mathrm{W}, 15^{\circ} \mathrm{S}-5^{\circ} \mathrm{N}\right),[S S T A]_{C}=$ the areaaveraged SSTA bounded by the region $\mathrm{C}\left(125^{\circ} \mathrm{E}-145^{\circ} \mathrm{E}, 10^{\circ} \mathrm{S}-20^{\circ} \mathrm{N}\right)$.

- NINO3.4- The area-averaged SSTA of the region bounded by $\left(5^{\circ} \mathrm{N}-5^{\circ} \mathrm{S}, 170^{\circ} \mathrm{W}-120^{\circ} \mathrm{W}\right)$ (Trenberth, 1997). This index was originally coined to represent the impacts of the canonical ENSO.

Henceforth, we compare the model predicted climate skills with the state-wise observed KRP, to quantify the climatic impact on the state-wise KRP. Further, we have used the one-tailed Student's t-test to assess the statistical significance of the correlation analysis. We calculate the area-averaged anomalous seasonal rainfall over the Indian subcontinent $\left(5^{\circ} \mathrm{N}-40^{\circ} \mathrm{N}, 60^{\circ} \mathrm{E}-100^{\circ} \mathrm{E}\right)$ during each JJAS season for observed data-set as well as CFSv2 seasonal and extended range model hindcasts. The significance of correlations has been determined from a one-tailed Student's t-test.

\section{Results}

\subsection{Analysis from the CFSv2 T382 seasonal hindcast}

\subsubsection{Correlations of anomalous observed and model-predicted rainfall}

The anomaly correlation coefficients between the observed ISMR and seasonal prediction hindcasts for the period 1981-2008 (Figure 1) are found to be 0.5, 0.36 and 0.22 from March, April and May initial conditions, respectively. As reported by Pokhrel et al., (2016) and Chattopadhyay et al., (2016), the threemonth lead forecast time has the maximum skill among the three, which is March's month. Here, The magnitude values of $0.5,0.36$ and 0.22 are statistically significant at $98 \%, 95 \%$ and $90 \%$ confidence interval respectively from a one-tailed Student t-test. This suggests that these seasonal forecasts of ISMR at 1-3 months lead are reasonably good.

We calculated the anomalous rainfall over the Indian region during El Niño (e.g.- for the March initial condition- 1984, 1987, 1988, 1993, 1995, 1997, 2001, 2002, 2004, 2006) , El Niño Modoki (e.g.- for the March initial condition-1981, 1984, 1991, 1992, 1993, 1996, 1998, 1999, 2002, 2004, 2008) and IOD (e.g.for the March initial condition-1982, 1984, 1986, 1988, 1992, 1994, 1998, 1999, 2004, 2005) events using both the observed and model-simulated for March April, and May initial conditions. Figures 2(a), suggests that during the 1981-2008 period, the canonical El Niño events, are associated with an anomalous deficit of rainfall across a significant part of the Indian subcontinent, such as along the monsoon trough, including central India, north India and the west coast of India. The corresponding model hindcasts (Figures $2 \mathrm{~d}, 2 \mathrm{~g}$ and $2 \mathrm{f}$ ) capture this signature. The aforementioned figures also suggest that the model hindcasts with April's initial condition are the most realistic, while the rainfall anomalies from those with March (May) initial condition are overestimated (underestimated) compared to observations. Figure 2(b) shows a strong summer monsoon rainfall reduction over India during the El Niño Modoki events, in conformation with the observational studies (e.g. Ashok et al., 2007; 2019). The hindcasts (Figures 2e, 2h and $2 \mathrm{k}$ ) are relatively good in the replication of the El Niño Modoki's impact, just like that of the El Niños. 
Also, the IOD linked anomalous rainfall with the March and April initial conditions can capture the surplus rainfall along the monsoon trough (Figures 2(c), 2(f) \& 2(i)).

\subsubsection{State-wise SMR (Observed \& CFSV2 T382 hindcast) Response to the KRP}

The seasonal hindcasts give us general guidance for long term strategic planning of water management for agriculture as well as other general purposes. Using linear correlation analysis, we evaluate the importance of summer monsoon rainfall (SMR) for the state-wide KRP from significant Kharif rice producing states in India. We carry out this analysis only for the 1990-2008 periods, owing to limited availability of seasonal hindcast data-sets.

Table 1 suggests that the correlations of the state-KRP with the observed local rainfall \& CFSv2 hindcast, over the period of 1981-2008, are simultaneously significant at $90 \%$ confidence level from a one-tailed Student's t-test for states like the UAP, Bihar \& Karnataka. These results are qualitatively similar to those for the shorter period of 2000-2013 (Amat and Ashok, 2018). Interestingly, the May initial condition correlations showing more significant results compared to the March and April initial conditions. Also, the negative results could be caused by crop damage. Several studies show that such a relationship can be attributed to the frequent floods/heavy rainfall damaging the crops (Kumar et al., 2004; Lal et al., 2020). A similar negative correlation is seen between the local KRP from Kerala with the local rainfall for a shorter period of 2001-2013 (Amat and Ashok, 2018).

The corresponding correlations of the observed state-level KRP with the model-predicted state-level SMR for the states like UAP, Bihar, Karnataka, MP, Odisha and WB from the Table 1 are qualitatively realistic although model predicted skills for most of the states are statistically insignificant. Only the states like Bihar and UAP have shown some statistically significant results mostly for the March and May initial conditions, which is a significant result for both observed and model hindcast. Apart from that, Punjab's negative relationship is well captured, but this weak correlation maybe because of the dry biases of CFSv2 over Indian region.

\subsubsection{Response of Climate Drivers (CFSv2 Seasonal hindcast) to that of the KRP}

In our recent publication (Amat and Ashok, 2018), we show that the KRP from several states such as the Karnataka, UAP, Odisha, etc., is significantly associated over the 2001-2013 period with the interannual variability of the tropical Indo-Pacific ocean drivers, specifically, the canonical ENSO, ENSO Modoki, and the IOD. We also show that this is potentially due to the modulation of the local moisture convergence by these drivers.

We compute the partial correlations of the KRP with various indices of various tropical Indo-Pacific drivers over the 1990-2008 period. The results are presented in Table 2. From the Table 2, we see that the 
model hindcasts capture the skills for MP with significant correlation magnitudes of -0.38 and -0.3 from the April and May initial conditions respectively, while the observed correlation is found to be -0.31 . The partial correlations from the hindcasts are comparable to that from the observations. Also, we find Bihar has some good results with the observed correlation magnitude -0.25 and -0.37 for April initial condition. Moreover, we find a high negative correlation of -0.47 between the observed NINO3 index and the observed KRP index over UAP. Also, the corresponding correlations of the KRP with hindcast NINO3 index from all initial conditions (March, April \& May) qualitatively capture the positive relationship, and the magnitudes are not significant for all three initial conditions. On the other hand, the observed IODMI exhibits a correlation of 0.26 with observed KRP over Odisha and the May initial condition capture this association pretty well with a magnitude of 0.28 . States like UAP, Punjab and Haryana have also given some good results, but the model shows opposite results concerning all the initial conditions. Interestingly, the observed positive association of the IODMI with the KRP is well-captured with the May initial once we partial out the correlations of the NINO3.4 index (Table 3). On the other hand, the predictive leads are not that impressive once we partial out the EMI impact (Table 4). The NINO3.4 index captures impact from both the canonical and Modoki ENSOs (e.g. Weng et al., 2007). The better representation of NIN03.4 index to isolate the effects over Bihar suggests that the summer monsoon rainfall is more sensitive to the sea surface temperature variations in the central tropical pacific (e.g. Krishna Kumar et al., 2006). This becomes clearer that because the hindcasts with April initial conditions also reasonably reproduce the observed positive correlations between the KRP over Bihar and the IODMI (Table 4) once the co-occurring impacts from the EMI are removed. Furthermore, the seasonal hindcasts with March, April and May excellently recapture the significant negative correlations for Bihar between the KRP and the EMI (Table 4).

From Table 3, we observe a significant negative correlation for Odisha, UP, Bihar and Haryana between the NINO3.4 index and the KRP index both for the observed and model-predicted different initial condition, mostly April and May. For Odisha, UAP, Bihar and Haryana, there is a statistically significant positive correlation between the IODMI \& KRP indices, after removing the impact of NINO3.4, in both the observed as well as the model outputs, in particular to April \& May initial conditions.

We can thus conjecture that the seasonal hindcasts of the CFSv2 reasonably reproduce the significant impacts of various tropical Indo-Pacific drivers on the KRP of UAP, Odisha and Bihar with a maximum lead of 2-3 months. The other skills include reproducing the observed and model-based negative correlations between the EMI and KRP over Bihar (Table 4) with all three initial conditions, i.e. March, April and May. On the other hand, the IODMI impact looks significant for Odisha when we remove the impact of EMI. By observing the results from Table 2, Table 3 and Table 4, we imply that the central Pacific SSTA index, i.e. NINO3.4 plays a significant role in the variation of seasonal Kharif rice production.

\subsection{Analysis from the CFSv2 Extended-Range hindcast:}

\subsubsection{Correlations of anomalous observed and model-predicted rainfall:}


We use the observed rainfall data-set and CFSv2 (T382 \& T126) extended-range hindcast outputs with the initial conditions with a 4-week leads (W01, W02, W03, W04), with the week one initial condition dated $31^{\text {st }}$ May of each year. We calculate the area-averaged anomalous rainfall over the Indian landmass during June through September (JJAS) from 2003 to 2016. For the extended range prediction, correlations with a magnitude of 0.7 and 0.4 are statistically significant at $99 \% \& 95 \%$ confidence interval from a one-tailed Student's t-test.

Figure 3 suggests that T126 based extended range hindcasts have positive correlations with the magnitudes $0.71,0.66,0.56, \& 0.44$ for the respective week leads of W01, W02, W03, W04; which is statistically significant at $99 \%$ confidence interval for W01 lead and then with a decreasing order as farther the week moves. We also observe that the variability of the predicted summer monsoon rainfall over the Indian region from extended range hindcast at both the resolution of $\sim 38 \mathrm{~km}$ (T382) \& 110km (T126) are reasonably realistic. Here, the observed rainfall during El Niño years has been depicted from the composite of 2007, 2012 and 2014. The observed IOD events, e.g., 2004, 2005, 2011, 2012, 2013, 2014 and the El Niño Modoki events, e.g., 2004, 2008 and 2010, have been considered. Figure 4(a), 4(d) \& $4(\mathrm{~g})$ suggests that the model captures a significant negative anomaly for the El Niño over central India. While Figures 4(b), 4(e) \& 4(h) suggest that model simulations are opposite to the observed negative rainfall anomaly over India, during the EI Niño Modoki events. In the extended range simulations, the signal may not be visible as clear as the seasonal hindcast because of data availability limitation.

Table 5 suggests that the correlation of EMI with the respective state-wise KRP for Bihar \& Karnataka with a magnitude of $-0.44 \&-0.43$, respectively, are statistically significant at a $95 \%$ confidence interval. There is a significant correlation for NINO3 \& KRP of Bihar with a magnitude of 0.61 , which is irrelevant to the observed one. UP has a significant correlation of NINO3.4 and the state-wise KRP with a magnitude of 0.62 , which is also irrelevant to the observed correlation. The model skills are not good enough to capture the skill for the state-wise Kharif rice forecast, while the observed data-set significantly captures it.

Table 6 suggests that the correlation of IODMI with the KRP of Bihar is statistically significant after removing the impact of NINO3, NINO3.4 \& EMI, with the magnitude of $0.61,0.69 \& 0.62$ respectively at a confidence interval of $99 \%$ from the one-tailed student t-test. In this case, both the data-sets (T126 \& T382) exhibit equally good skill for Bihar. Also, the correlation of IODMI with the KRP of Karnataka has a statistically significant skill, after removing the impact of EMI. We observe that the skill for IODMI with $\mathrm{KRP}$ relation is significant for a few states. Also, the non-significant values exhibit relevant sign convention for the observed skills of all other states. While in the previous correlation Table (Table 5), most of the states show unrealistic correlation coefficients, despite having a significant magnitude.

\section{Conclusion}

The economy of most Indian states is governed by agricultural yield, which still largely depends on monsoon rainfall (e.g., Amat et al., 2018). In the present study, we explore the potential utility of the hindcasts from the state of the art IITM dynamical seasonal and extended hindcast systems. To this end, 
we use the available (i) quasi-operational seasonal hindcast products available for 1981-2008 period at $38 \mathrm{~km}$ resolution, (ii) and hindcasts of extended range prediction for the 2003-2016 period available at both $110 \mathrm{~km}$ and $38 \mathrm{~km}$ resolution. Observations-based data-sets have been used to ascertain the relevance of local rainfall variability and its association with its important drivers, specifically, the cooccurring ENSO, ENSO Modoki, and the Indian Ocean Dipole. Our observational analysis shows that the association between state-wise summer monsoon rainfall and KRP rice production is statistically significant at 90\% - 95\% confidence level over UAP, Bihar, Karnataka, MP, Odisha and WB for the period 1990-2008, for which the seasonal hindcast is available. The Kharif rice production (KRP) of UP, MP, Bihar and Haryana are significantly associated with the NINO3 and NINO3.4 indices. The IOD events significantly influence the KRP of Odisha, Bihar, and Haryana states. Equipped with these observations, we estimate the correlations of (i) the simulated local rainfall with the local KRP, and (ii) correlations of the indices each simulated climate driver with the observed KRP; and A realistic correlation would mean that the predicted climate signals from the IITM CFS system can be used to predict KRP of the relevant states statistically.

As far as the seasonal hindcasts are concerned, we find that the correlations between the predicted and observed area-averaged seasonal Indian summer monsoon rainfall anomaly with the initial conditions of March, April and May are, respectively, 0.5, 0.36, and 0.22. The March and April correlations are statistically significant at $95 \%$ confidence level at one-tailed t-test. The corresponding seasonal mean anomaly correlations for the generated by concatenating various extended range hindcasts, at various leads of $1,2,3$ and 4 weeks are $0.71,0.66,0.56$, and 0.44 respectively. All these lead forecasts are statistically significant at a $99 \%$ confidence level from a one-tailed Student's t-test.

These moderate but significant skills, motivated us to determine whether the rainfall forecasts have any statistically significant relationship with observed Kharif rice production. So we carried out further analysis in this context. Encouragingly, these associations are well captured by the seasonal forecasting hindcast data-set from a qualitative sense. To be clear, while the seasonal retrospective forecasts simulate the sign of the correlation of climate Indices with rice production for these states well, the association is statistically significant for few states such as Kerala. Moreover, we also found severe crop damage due to heavy rainfall and subsequent flooding (Kumar et al., 2004; Lal et al., 2020).

The extended range prediction hindcast captures the association of local Kharif rice production with summer monsoon rainfall in India's various states. Similarly, the association of Indian Ocean SST conditions and KRP production for WB, Bihar and Karnataka are clearly indicated in the analysis of extended range products. In a nutshell, the correlations between the local KRP with the co-occurring tropical Indo-pacific driver signals predicted by the models are better for the states located at the east coast of India and in the monsoon trough regions. While the current correlations between the KRP of several states with the hindcast rainfall and/or various tropical Indo-pacific drivers are statistically significant, these are realistic enough to be directly used to predict the local KRP, in a deterministic sense. However, the skills can be harnessed to develop a potentially useful forecast product of local KRP in 
states such as UAP, MP, Bihar and Odisha by processing these significant skills of the IITM CFS forecasting system through various statistical-dynamical downscaling techniques.

\section{Declarations}

\section{Acknowledgements}

We acknowledge Mr Kiran Salunke, Indian Institute of Tropical Meteorology, Pune, India, for their assistance while extracting IITM-CFS data. Also, We acknowledge the University Grants Commission \& the Ministry of Tribal Affairs, Government of India, for providing the research fellowship. Also, we are thankful to our reviewers for their valuable comments and kind suggestions. Figures in the manuscript have been created using the COLA/GrADS.

Funding: UGC- Rajiv Gandhi National Fellowship, Government of India.

Conflicts of Interest/Competing interests: Not applicable

Availability of data and material: The HadISST data set has been downloaded from < https://www.metoffice.gov.uk/hadobs/hadisst/ >. IMD rainfall and CFSv2 seasonal and extended-range hindcast data sets have been collected from IITM, Pune. The crop data set has been downloaded from < indiastats.com $>$, which is provided by the Govt. of India.

Code availability: All the calculations and plots have been done using various tools such as NCL, Grads and CDO.

\section{Authors' contributions:}

Hemadri Bhusan Amat did all the calculations, analysis and wrote the manuscript by taking inputs from all the co-authors. Maheswar Pradhan \& Suryachandra A. Rao provided the IITM-CFSv2 seasonal hindcast data set and co-wrote the manuscript. Charan Teja Tejavath helped in collecting the agriculture data sets used in this study and assisted in the analysis and co-wrote the manuscript. Avijit Dey \& Atul Kumar Sahaiprovided the IITM-CFSv2 extended-range hindcast data analysis and contributed to the manuscript. Karumuri Ashok (Corresponding author) conceived the problem, and the co-wrote the manuscript.

\section{References}

1. Amat, H. B., \& Ashok, K. (2018). Relevance of Indian Summer Monsoon and its Tropical Indo-Pacific Climate Drivers for the Kharif Crop Production. Pure and Applied Geophysics, 175(6), 2307-2322. https://doi.org/10.1007/s00024-017-1758-9

2. Abhilash, S., Sahai, A. K., Pattnaik, S., Goswami, B. N., \& Kumar, A. (2014). Extended range prediction of active-break spells of Indian summer monsoon rainfall using an ensemble prediction system in 
NCEP Climate Forecast System. International Journal of Climatology, 34(1), 98-113. https://doi.org/10.1002/joc.3668

3. Abhilash, S., Mandal, R., Dey, A., Phani, R., Joseph, S., Chattopadhyay, R., et al. (2018). Role of enhanced synoptic activity and its interaction with intra-seasonal oscillations on the lower extended range prediction skill during 2015 monsoon season. Climate Dynamics, 51(9-10), 3435-3446. https://doi.org/10.1007/s00382-018-4089-3

4. Ashok, K., Guan, Z., \& Yamagata, T. (2001). Impact of the Indian Ocean Dipole on the relationship between the Indian Monsoon Rainfall and ENSO.. Geophysical Research Letters, 28(23), 4499-4502. https://doi.org/10.1029/2001GL013294

5. Ashok, K., Guan, Z., Saji, N. H., \& Yamagata, T. (2004). Individual and Combined Influences of ENSO and the Indian Ocean Dipole on the Indian Summer Monsoon. American Meterological Society, 17, 3141-3155. https://doi.org/10.1175/1520-0442(2004)017<3141:IACIOE>2.0.CO;

6. Ashok K, Behera S, Rao AS, Weng H, Yamagata T (2007) El Niño Modoki and its teleconnection. J Geophys Res 112:C11007.doi:10.1029/2006JC003798

7. Ashok, K., \& Saji, N. H. (2007). On the impacts of ENSO and Indian Ocean dipole events on subregional Indian summer monsoon rainfall. Natural Hazards, 42(2), 273-285. https://doi.org/10.1007/s11069-006-9091-0

8. Ashok, K., lizuka, S., Rao, S. A., Saji, N. H., \& Lee, W. J. (2009). Processes and boreal summer impacts of the 2004 El Niño Modoki: An AGCM study. Geophysical Research Letters, 36(4), 1-5. https://doi.org/10.1029/2008GL036313

9. Ashok K, Feba F, \& Tejavath CT (2019). The Indian summer monsoon rainfall and ENSO. Mausam, 70(3), 443-452.

10. Behera, S. K., J.-J. Luo, S. Masson, P. Delecluse, S. Gualdi, A. Navarra, and T. Yamagata (2005), Paramount impact of the Indian Ocean dipole on the East African short rains: A CGCM study, J. Clim., $18,4514-4530$.

11. Borah, N., Sahai, A. K., Chattopadhyay, R., Joseph, S., Abhilash, S., \& Goswami, B. N. (2013). A selforganizing map-based ensemble forecast system for extended range prediction of active/break cycles of Indian summer monsoon. Journal of Geophysical Research Atmospheres, 118(16), 90229034. https://doi.org/10.1002/jgrd.50688

12. Chattopadhyay, R., Rao, S. A., Sabeerali, C. T., George, G., Rao, D. N., Dhakate, A., \& Salunke, K. (2016). Large-scale teleconnection patterns of Indian summer monsoon as revealed by CFSv2 retrospective seasonal forecast runs. International Journal of Climatology, 36(9), 3297-3313. https://doi.org/10.1002/joc.4556

13. Chattopadhyay N, Rao K V, Sahai A K, Balasubramanian R, Pai D S, Pattanaik D R., Khedikar S (2018). Usability of extended range and seasonal weather forecast in Indian agriculture. Mausam, 69(1), 29-44.

14. Chattopadhyay R, Joseph S, Abhilash S, Mandal R, Dey A, Phani R., Sahai A K (2019). Understanding the intraseasonal variability over Indian region and development of an operational extended range 
prediction system. Mausam, 70(1), 31-56.

15. Dai,A., and T.Wigley, 2000 : Global patterns of ENSO-induced precipitation. Res. Lett.,27,12831286,https://doi.org/10.1029/1999GL011140.

16. Gadgil S \& Gadgil Siddhartha (2006). The Indian monsoon, GDP and agriculture. Economic \& Political Weekly, 41(25th November), 4887-4895. https://doi.org/10.2307/4418949

17. Guan, Z., K. Ashok, and T. Yamagata (2003a), The summertime response of the tropical atmosphere to the Indian Ocean sea surface temperature anomalies, J. Metor. Soc. Japan, 81, $533-561$.

18. Hameed, S. N. The indian ocean dipole. In Oxford Research Encyclopedia of Climate Science (Oxford University Press, 2018)

19. Jadhav, J., Swapna, P., Shamal, M., \& Ashok, K. (2015). On the possible cause of distinct El Niño types in the recent decades. Scientific Reports, 5, 1- 21. https://doi.org/10.1038/srep17009

20. Jeong, H. I., Lee, D. Y., Ashok, K., Ahn, J. B., Lee, J. Y., Luo, J. J., ... Ham, Y. G. (2012). Assessment of the APCC coupled MME suite in predicting the distinctive climate impacts of two flavors of ENSO during boreal winter. Climate Dynamics, 39(1-2), 475-493. https://doi.org/10.1007/s00382-0121359-3

21. Joseph, S., Sahai, A. K., Chattopadhyay, R., Sharmila, S., Abhilash, S., Rajeevan, M., et al. (2016). Extremes in June rainfall during the Indian summer monsoons of 2013 and 2014: Observational analysis and extended-range prediction. Quarterly Journal of the Royal Meteorological Society, 142(696), 1276-1289. https://doi.org/10.1002/qj.2730

22. Ju J, Slingo J (1995) The Asian summer monsoon and ENSO. Q J R Meteorol Soc 121(525):11331168

23. Kao, H. Y., \& Yu, J. Y. (2009). Contrasting Eastern-Pacific and Central-Pacific types of ENSO. Journal of Climate, 22(3), 615-632. https://doi.org/10.1175/2008JCLI2309.1

24. Keshavamurty, R. (1982). Response of the atmosphere to sea surface temperature anomalies over the equatorial Pacific and the teleconnections of the Southern Oscillation. Journal of the Atmospheric Sciences, Vol. 39, pp. 1241-1259. https://doi.org/10.1175/15200469(1982)039<1241:ROTATS >2.0.CO;2

25. Krishna Kumar, K., Rupa Kumar, K., Ashrit, R. G., Deshpande, N. R., \& Hansen, J. W. (2004). Climate impacts on Indian agriculture. International Journal of Climatology, 24(11), 1375-1393. https://doi.org/10.1002/joc.1081

26. Krishnaswamy, J., Vaidyanathan, S., Rajagopalan, B., Bonell, M., Sankaran, M., Bhalla, R. S., \& Badiger, S. (2015). Non-stationary and non-linear influence of ENSO and Indian Ocean Dipole on the variability of Indian monsoon rainfall and extreme rain events. Climate Dynamics, 45(1-2), 175-184. https://doi.org/10.1007/s00382-014-2288-0

27. Kug, J. S., Choi, J., An, S. II, Jin, F. F., \& wittenberg, A. T. (2010). Warm pool and cold tongue El Ni??o events as simulated by the GFDL 2.1 coupled GCM. Journal of Climate, 23(5), 1226-1239. https://doi.org/10.1175/2009JCLI3293.1 
28. Kumar, K. K. et al. 2006. "Unraveling the Mystery of Indian Monsoon Failure During El Niño." Science 314(5796): 115-19. http://www.sciencemag.org/cgi/doi/10.1126/science.1131152.

29. Lal, P., Prakash, A., Kumar, A., Srivastava, P. K., Saikia, P., Pandey, A. C., et al. (2020). Evaluating the 2018 extreme flood hazard events in Kerala, India. Remote Sensing Letters, 11(5), 436-445. https://doi.org/10.1080/2150704X.2020.1730468

30. Marathe, S., Ashok, K., Swapna, P., \& Sabin, T. P. (2015). Revisiting El Niño Modokis. Climate Dynamics, 45(11-12), 3527-3545. https://doi.org/10.1007/s00382-015-2555-8

31. Murtugudde, R., McCreary, J. P., \& Busalacchi, A. J. (2000). Oceanic processes associated with anomalous events in the Indian Ocean with relevance to 1997-1998. Journal of Geophysical Research, 105(C2), 3295. https://doi.org/10.1029/1999JC900294

32. Navarra A, Ward MN, Miyakoda K (1999) Tropical-wide teleconnection and oscillation. I: teleconnection indices and type I/type II states. Quart J Roy Meteor Soc 125:2909-2935

33. Nicholls, N. (1983). Predicting Indian monsoon rainfall from sea-surface temperature in the Indonesia-north Australia area. Nature, 306, 576-577.

34. Pai D. S., Sridhar L, Rajeevan M., Sreejith O P, Satbhai N S \& Mukhopadyay B (2014). Development of a new high spatial resolution $\left(0.25^{\circ} \times 0.25^{\circ}\right)$ Long Period (1901-2010) daily gridded rainfall data set over India and its comparison with existing data sets over the region data sets of different spatial resolutions and time period, 1(January), 1-18.

35. Pai, D. S., Suryachandra Rao, A., Senroy, S., Pradhan, M., Pillai, P. A., \& Rajeevan, M. (2017).

Performance of the operational and experimental long-range forecasts for the 2015 southwest monsoon rainfall. Current Science, 112(1), 68-75. https://doi.org/10.18520/cs/v112/i01/68-75

36. Palmer, T. N., Branković, Viterbo, P., \& Miller, M. J. (1992). Modeling interannual variations of summer monsoons. Journal of Climate, Vol. 5, pp. 399-417. https://doi.org/10.1175/1520-

0442(1992)005<0399:MIVOSM>2.0.C0;2

37. Pattanaik D R, Sahai A K, Mandal R, Phani Muralikrishna R, Dey A, Chattopadhyay R, Mishra V (2019). Evolution of operational extended range forecast system of IMD: Prospects of its applications in different sectors. Mausam, 70(2), 233-264.

38. Pradhan, M., Rao, A. S., Srivastava, A., Dakate, A., Salunke, K., \& Shameera, K. S. (2017). Prediction of Indian Summer-Monsoon Onset Variability: A Season in Advance. Scientific Reports, 7(1), 1-14. https://doi.org/10.1038/s41598-017-12594-y

39. Prasanna, V. (2014). Impact of monsoon rainfall on the total foodgrain yield over India. Journal of Earth System Science, 123(5), 1129-1145. https://doi.org/10.1007/s12040-014-0444-x

40. Pokhrel, S., Saha, S. K., Dhakate, A., Rahman, H., Chaudhari, H. S., Salunke, K., et al. (2016). Seasonal prediction of Indian summer monsoon rainfall in NCEP CFSv2: Forecast and predictability error. Climate Dynamics, 46(7-8), 2305-2326. https://doi.org/10.1007/s00382-015-2703-1

41. Ramu, D. A., C. T. Sabeerali,R. Chattopadhyay, D. N. Rao, G. George,A. R. Dhakate, K. Salunke, A. Srivastava, and S. A. Rao (2016), Indian summer monsoon rainfall simulation and prediction skill in 
the CFSv2 coupled model: Impact of atmospheric horizontal resolution, J. Geophys. Res. Atmos., 121, 2205-2221, doi:10.1002/2015JD024629.

42. Rao, S. A., Goswami, B. N., Sahai, A. K., Rajagopal, E. N., Mukhopadhyay, P., Rajeevan, M., ... Maini, P. (2019). Monsoon mission a targeted activity to improve monsoon prediction across scales. Bulletin of the American Meteorological Society, 100(12), 2509-2532. https://doi.org/10.1175/BAMS-D-170330.1

43. Ratnam, J. V., S. K. Behera, Y. Masumoto, T. Takahashi, and T. Yamagata (2010), Pacific ocean origin for the 2009 Indian summer monsoon failure, Geophys. Res. Lett., 37, L07807, doi:10.1029/2010GL042798

44. Rayner, N. A., Parker, D. E., Horton, E. B., Folland, C. K., Alexander, L. V., Rowell, D. P., ... Kaplan, A. (2003). Global analyses of sea surface temperature, sea ice, and night marine air temperature since the late nineteenth century. Journal of Geophysical Research, 108(D14), 4407. https://doi.org/10.1029/2002JD002670

45. Saha, S., Moorthi, S., Pan, H. L., Wu, X., Wang, J., Nadiga, S., Goldberg, M. (2010). The NCEP climate forecast system reanalysis. Bulletin of the American Meteorological Society, 91(8), 1015-1057. https://doi.org/10.1175/2010BAMS3001.1

46. Saha, S., Moorthi, S., Wu, X., Wang, J., Nadiga, S., Tripp, P., et al. (2013). The NCEP climate forecast system version 2. Journal of Climate, 27(6), 2185-2208. https://doi.org/10.1175/JCLI-D-12-00823.1

47. Sahai, A. K., et al. "Simulation and Extended Range Prediction of Monsoon Intraseasonal Oscillations in NCEP CFS/GFS Version 2 Framework." Current Science, vol. 104, no. 10, 2013, pp. 13941408. JSTOR, www.jstor.org/stable/24092513

48. Sahai A K et al., (2016). Extended Range Prediction System and its Application. Vayu Mandal, 42(2), 75-96.

49. Saji, N. H., Goswami, B. N., Vinayachandran, P. N., \& Yamagata, T. (1999). A dipole mode in the tropical Indian Ocean. Nature, 401(6751), 360-363. https://doi.org/10.1038/43854

50. Saranya Ganesh, S., Sahai, A. K., Abhilash, S., Joseph, S., Dey, A., Mandal, R., et al. (2018). A New Approach to Improve the Track Prediction of Tropical Cyclones Over North Indian Ocean. Geophysical Research Letters, 45(15), 7781-7789. https://doi.org/10.1029/2018GL077650

51. Sharmila, S., Pillai, P. A., Joseph, S., Roxy, M., Krishna, R. P. M., Chattopadhyay, R., Goswami, B. N. (2013). Role of ocean-atmosphere interaction on northward propagation of Indian summer monsoon intra-seasonal oscillations (MISO). Climate Dynamics, 41(5-6), 1651-1669.

https://doi.org/10.1007/s00382-013-1854-1

52. Shukla, J. and Paolina, D. A., 1983, "The southern oscillation and long range forecasting of the summer monsoon rainfall over India", Mon. Weather Rev., 111, 1830-1837, doi: 10.1175/1520-0493.

53. Sikka, D. R., \& Gadgil, S. (1980). On the Maximum Cloud Zone and the ITCZ over Indian, Longitudes during the Southwest Monsoon. Monthly Weather Review, Vol. 108, pp. 1840-1853.

https://doi.org/10.1175/1520-0493(1980)108<1840:OTMCZA>2.0.CO;2 
54. Soman, M. K., \& Slingo, J. (1997). Sensitivity of the Asian summer monsoon to aspects of seasurface-temperature anomalies in the tropical Pacific ocean. Quarterly Journal of the Royal Meteorological Society, 123(538), 309-336. https://doi.org/10.1256/smsqj.53803

55. Srivastava A, Pradhan M, George G, Dhakate A, Salunke K, \& Rao S A. (2015). A Research Report on the 2015 Southwest Monsoon. (November), 58-62. Retrieved from http://www.tropmet.res.in/ lip/Publication/RR-pdf/RR-185.pdf

56. Srivastava, A., Rao, S. A., Rao, D. N., George, G., \& Pradhan, M. (2017). Structure, characteristics, and simulation of monsoon low-pressure systems in CFSv2 coupled model. Journal of Geophysical Research: Oceans, 122(8), 6394-6415. https://doi.org/10.1002/2016JC012322

57. Varikoden, H., \& Preethi, B. (2013). Wet and dry years of Indian summer monsoon and its relation with Indo-Pacific sea surface temperatures. International Journal of Climatology, 33(7), 1761-1771. https://doi.org/10.1002/joc.3547

58. Webster, P. J., Moore, A. M., Loschnigg, J. P., \& Leben, R. R. (1999). Coupled ocean-atmosphere dynamics in the Indian Ocean during 1997-98. Nature, 401(6751), 356-360.

https://doi.org/10.1038/43848

59. Weng, H., Ashok, K., Behera, S. K., Rao, S. A., \& Yamagata, T. (2007). Impacts of recent El Niño Modoki on dry/wet conditions in the Pacific rim during boreal summer. Climate Dynamics, 29(2-3), 113129. https://doi.org/10.1007/s00382-007-0234-0

60. Yamagata, T., Behera, S., Rao, S., Guan, Z., Ashok, K., \& Saji, H. (2003). Comments on "Dipoles, Temperature Gradients, and Tropical Climate Anomalies". Bulletin of the American Meteorological Society,84(10), 1418-1422. Retrieved 25th April, 2020, from jstor.org/stable/26216895

\section{Tables}

Table 1: Correlations between the state-wise Kharif rice production (KRP) with the observed \& CFSv2 Seasonal (March, April and May initial conditions) hindcast rainfall of that state for the 1981-2008 period. All bold values are the correlations with value, and 0.24 are statistically significant at $90 \%$ confidence level from a one-tailed student t-test. 


\begin{tabular}{|lllll|}
\hline States & Observed & \multicolumn{2}{c|}{ Model } & \\
\cline { 3 - 5 } & & March & April & May \\
\hline Bihar & $\mathbf{0 . 3 8}$ & 0.18 & $\mathbf{0 . 2 7}$ & $\mathbf{0 . 2 7}$ \\
\hline Haryana & 0.13 & -0.13 & -0.11 & 0.11 \\
\hline Karnataka & $\mathbf{0 . 2 6}$ & -0.11 & 0.06 & $\mathbf{0 . 3 5}$ \\
\hline Kerala & 0.21 & 0.11 & 0.1 & 0.007 \\
\hline MP & $\mathbf{0 . 4 6}$ & 0.12 & 0.11 & -0.07 \\
\hline Odisha & $\mathbf{0 . 6 4}$ & 0.006 & 0.02 & 0.007 \\
\hline Punjab & -0.12 & -0.21 & -0.36 & 0.1 \\
\hline UAP & $\mathbf{0 . 5 9}$ & $\mathbf{0 . 2 8}$ & 0.12 & $\mathbf{0 . 5 1}$ \\
\hline UP & -0.02 & -0.07 & -0.11 & 0.05 \\
\hline WB & $\mathbf{0 . 3}$ & -0.22 & 0.11 & 0.1 \\
\hline
\end{tabular}

Table 2: Partial correlations between the observed state-wise KRP with the observed Nino3 \& IODMI for the period of 1981-2008, and those drivers from the model hindcast. The magnitude with 0.24 and 0.31 are statistically significant at $90 \%$ and $95 \%$ confidence interval respectively from one-tailed Student's ttest and are shown in bold. 


\begin{tabular}{|c|c|c|c|c|c|c|c|c|}
\hline \multirow[t]{2}{*}{ States } & \multicolumn{4}{|c|}{ NIN03-KRP adjusted for (IODMI) } & \multicolumn{4}{|c|}{ IODMI-KRP adjusted for (NINO3) } \\
\hline & Observed & March & April & May & Observed & March & April & May \\
\hline Bihar & -0.25 & -0.21 & -0.37 & -0.22 & 0.2 & -0.22 & 0.15 & 0.01 \\
\hline Haryana & -0.28 & 0.28 & 0.31 & 0.35 & 0.32 & -0.22 & -0.2 & -0.29 \\
\hline Karnataka & -0.2 & 0.24 & 0.19 & 0.26 & 0.19 & -0.18 & 0.07 & -0.28 \\
\hline Kerala & 0.17 & -0.32 & -0.27 & -0.33 & -0.16 & 0.34 & 0.2 & 0.35 \\
\hline MP & -0.31 & -0.18 & -0.38 & -0.3 & -0.11 & 0.07 & 0.38 & 0.14 \\
\hline Odisha & -0.27 & 0.05 & -0.06 & 0.05 & 0.26 & -0.01 & 0.28 & -0.01 \\
\hline Punjab & -0.2 & 0.37 & 0.38 & 0.38 & 0.27 & -0.29 & -0.21 & -0.30 \\
\hline UAP & -0.47 & 0.05 & 0.05 & 0.13 & 0.31 & -0.28 & -0.02 & -0.3 \\
\hline UP & -0.26 & 0.26 & 0.11 & 0.22 & 0.22 & 0.30 & 0.03 & -0.25 \\
\hline WB & -0.19 & 0.36 & 0.27 & 0.34 & 0.19 & -0.28 & -0.07 & 0.31 \\
\hline
\end{tabular}

Table 3: Partial correlations between the observed state-wise KRP with the observed NINO3.4 \& IODMI for the period of 1981-2008, and those drivers from the model hindcast. The magnitude with 0.24 and 0.31 are statistically significant at $90 \%$ and $95 \%$ confidence interval respectively from one-tailed Student t-test and are shown in bold. 


\begin{tabular}{|c|c|c|c|c|c|c|c|c|}
\hline \multirow[t]{2}{*}{ States } & \multicolumn{4}{|c|}{ NIN03.4-KRP adjusted for (IODMI) } & \multicolumn{4}{|c|}{ IODMI-KRP adjusted for (NINO3.4) } \\
\hline & Observed & March & April & May & Observed & March & April & May \\
\hline Bihar & -0.4 & -0.21 & -0.45 & -0.29 & 0.28 & -0.21 & 0.26 & 0.24 \\
\hline Haryana & -0.24 & 0.28 & 0.25 & 0.29 & 0.30 & -0.22 & -0.18 & -0.26 \\
\hline Karnataka & -0.23 & 0.27 & 0.15 & 0.2 & 0.19 & -0.2 & 0.07 & -0.25 \\
\hline Kerala & 0.14 & -0.31 & -0.2 & -0.24 & -0.14 & 0.33 & 0.17 & 0.31 \\
\hline MP & -0.09 & -0.15 & -0.25 & -0.27 & -0.08 & 0.06 & 0.38 & 0.13 \\
\hline Odisha & -0.26 & 0.1 & -0.24 & -0.05 & 0.24 & -0.03 & 0.29 & 0.25 \\
\hline Punjab & -0.12 & 0.38 & 0.33 & 0.34 & 0.23 & -0.25 & -0.21 & -0.27 \\
\hline UAP & -0.55 & 0.16 & -0.04 & 0.02 & 0.34 & -0.28 & 0.02 & 0.25 \\
\hline UP & -0.28 & -0.26 & 0.03 & 0.17 & 0.22 & -0.3 & 0.06 & -0.23 \\
\hline WB & -0.1 & 0.39 & 0.24 & 0.35 & 0.14 & 0.3 & -0.07 & -0.31 \\
\hline
\end{tabular}

Table 4: Partial correlations between the observed state-wise KRP with the observed EMI \& IODMI for the period of 1981-2008, and those drivers from the model hindcast. The magnitude with 0.24 and 0.31 are statistically significant at $90 \%$ and $95 \%$ confidence interval respectively from one-tailed Student's t-test and are shown in bold. 


\begin{tabular}{|lllllllll|}
\hline \multirow{2}{*}{ States } & \multicolumn{3}{l}{ EMI-KRP adjusted for (IOD) } & \multicolumn{5}{c|}{ IOD-KRP adjusted for (EMI) } \\
\cline { 2 - 6 } & Observed & March & April & May & Observed & March & April & May \\
\hline Bihar & -0.35 & -0.14 & -0.39 & -0.29 & 0.09 & -0.23 & 0.2 & 0.02 \\
\hline Haryana & 0.01 & $\mathbf{0 . 2 5}$ & -0.06 & -0.05 & 0.21 & -0.21 & -0.03 & -0.09 \\
\hline Karnataka & -0.08 & $\mathbf{0 . 3 3}$ & -0.1 & -0.04 & 0.09 & -0.24 & 0.18 & -0.14 \\
\hline Kerala & 0.03 & -0.19 & 0.09 & 0.1 & -0.09 & $\mathbf{0 . 2 8}$ & 0.03 & 0.16 \\
\hline MP & -0.14 & -0.05 & -0.09 & 0.03 & -0.13 & -0.01 & $\mathbf{0 . 2 5}$ & -0.03 \\
\hline Odisha & 0.03 & $\mathbf{0 . 3 1}$ & -0.15 & 0.03 & $\mathbf{0 . 2 4}$ & -0.16 & $\mathbf{0 . 3 2}$ & 0.01 \\
\hline Punjab & 0.13 & $\mathbf{0 . 3 7}$ & 0.04 & 0.04 & 0.2 & -0.25 & -0.06 & -0.12 \\
\hline UAP & -0.23 & 0.17 & $-\mathbf{0 . 3 6}$ & -0.07 & 0.05 & -0.28 & 0.20 & -0.14 \\
\hline UP & -0.06 & $\mathbf{0 . 2 5}$ & 0.2 & -0.06 & 0.1 & -0.30 & 0.17 & -0.12 \\
\hline WB & 0.15 & $\mathbf{0 . 4}$ & 0.05 & 0.18 & 0.11 & -0.31 & 0.01 & -0.22 \\
\hline
\end{tabular}

Table 5: Partial correlations between the state-wise KRP with the NINO3, NINO3.4 \& EMI, and removing the impact of IODMI for the period of 2003-2015. Correlations with a magnitude above $0.36 \& 0.45$ are statistically significant at $90 \% \& 95 \%$ confidence level respectively, from a one-tailed t-test and are shown in bold. 


\begin{tabular}{|c|c|c|c|c|c|c|c|c|c|}
\hline \multirow[t]{2}{*}{ States } & \multicolumn{3}{|c|}{$\begin{array}{l}\text { Correlation of NINO3\& } \\
\text { KRP, adjusted } \\
\text { for IODMI }\end{array}$} & \multicolumn{3}{|c|}{$\begin{array}{l}\text { Correlation of NINO3.4 \& } \\
\text { KRP, adjusted } \\
\text { for IODMI }\end{array}$} & \multicolumn{3}{|c|}{$\begin{array}{l}\text { Correlation of EMI \& KRP, } \\
\text { adjusted } \\
\text { for IODMI }\end{array}$} \\
\hline & T126 & OBS & T382 & T126 & OBS & T382 & T126 & OBS & T382 \\
\hline Bihar & 0.61 & -0.11 & 0.27 & 0.27 & -0.21 & 0.27 & -0.44 & -0.38 & -0.44 \\
\hline Haryana & 0.07 & -0.38 & 0.08 & -0.29 & -0.54 & -0.29 & 0.37 & -0.56 & 0.37 \\
\hline Karnataka & -0.32 & -0.43 & -0.07 & 0.22 & -0.63 & 0.22 & -0.43 & -0.68 & -0.43 \\
\hline Kerala & 0.02 & 0.42 & -0.06 & 0.14 & 0.54 & 0.14 & -0.42 & 0.58 & -0.42 \\
\hline MP & 0.03 & -0.17 & 0.56 & -0.21 & -0.17 & -0.21 & 0.56 & -0.14 & 0.56 \\
\hline Odisha & 0.02 & -0.30 & -0.03 & 0.00 & -0.36 & 0.00 & 0.37 & -0.31 & 0.37 \\
\hline Punjab & -0.03 & -0.01 & 0.14 & 0.16 & -0.22 & 0.16 & 0.43 & -0.52 & 0.43 \\
\hline UAP & 0.01 & -0.68 & -0.2 & -0.31 & -0.77 & -0.31 & 0.18 & -0.60 & 0.18 \\
\hline UP & 0.11 & -0.39 & 0.04 & 0.63 & -0.50 & 0.63 & 0.25 & -0.49 & 0.25 \\
\hline WB & -0.05 & 0.38 & 0.15 & 0.25 & 0.42 & 0.25 & 0.46 & 0.22 & 0.46 \\
\hline
\end{tabular}

Table 6: Partial correlation setween the state-wise KRP with the IODMI \& removing the impact of NINO3, NINO3.4 and EMI for the period of 2003-2015. Correlations with a magnitude above $0.36 \& 0.45$ are statistically significant at $90 \% \& 95 \%$ confidence level respectively, from a one-tailed t-test and are shown in bold. 


\begin{tabular}{|c|c|c|c|c|c|c|c|c|c|}
\hline \multirow[t]{3}{*}{ States } & \multicolumn{3}{|c|}{$\begin{array}{l}\text { Correlation of IODMI \& } \\
\text { KRP, adjusted } \\
\text { for NINO3 }\end{array}$} & \multicolumn{3}{|c|}{$\begin{array}{l}\text { Correlation of IODMI \& } \\
\text { KRP, adjusted } \\
\text { for NINO } 3.4\end{array}$} & \multicolumn{3}{|c|}{$\begin{array}{l}\text { Correlation of IODMI \& KRP, } \\
\text { adjusted } \\
\text { for EMI }\end{array}$} \\
\hline & & OBS & T382 & & OBS & T382 & T126 & OBS & T382 \\
\hline & T126 & & & T126 & & & & & \\
\hline Bihar & 0.61 & 0.68 & 0.61 & 0.66 & 0.69 & 0.66 & 0.62 & 0.60 & 0.95 \\
\hline Haryana & 0.07 & 0.48 & 0.07 & 0.06 & 0.46 & 0.09 & 0.23 & 0.17 & 0.16 \\
\hline Karnataka & -0.32 & -0.07 & -0.32 & -0.32 & -0.22 & -0.33 & -0.53 & -0.53 & -0.46 \\
\hline Kerala & 0.02 & -0.54 & 0.02 & 0.05 & -0.52 & 0.01 & -0.15 & -0.24 & -0.03 \\
\hline MP & 0.03 & 0.24 & 0.03 & 0.15 & 0.21 & 0.15 & 0.34 & 0.13 & 0.59 \\
\hline Odisha & 0.02 & 0.13 & 0.02 & -0.02 & 0.06 & 0.02 & 0.15 & -0.09 & 0.01 \\
\hline Punjab & -0.03 & 0.23 & -0.03 & -0.04 & 0.24 & 0.02 & 0.16 & -0.01 & 0.09 \\
\hline UAP & 0.01 & 0.66 & 0.01 & -0.05 & 0.62 & -0.02 & 0.02 & 0.23 & -0.14 \\
\hline UP & 0.11 & 0.48 & 0.11 & 0.10 & 0.44 & 0.11 & 0.21 & 0.19 & 0.17 \\
\hline WB & -0.05 & -0.07 & -0.05 & -0.07 & 0.03 & -0.02 & 0.16 & 0.13 & 0.07 \\
\hline
\end{tabular}

Figures 

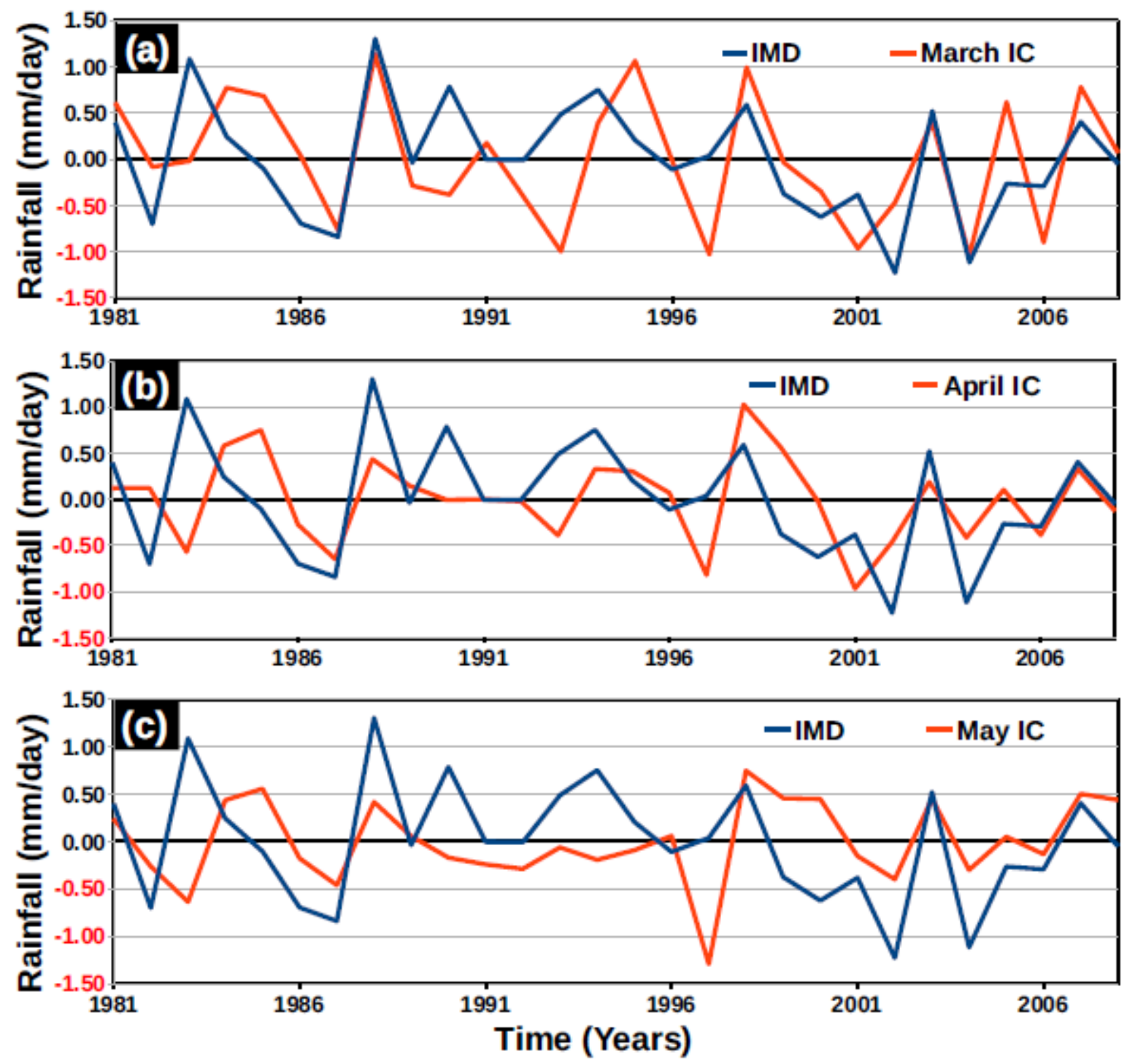

Figure 1

Observed(IMD) time series of area-averaged JJAS rainfall anomaly (blue), shown with those from the CFSv2 T382 seasonal hindcast (mm/day; red) with different initial conditions (a) March, (b) April, and (c) May during 1981 to 2008 respectively. 


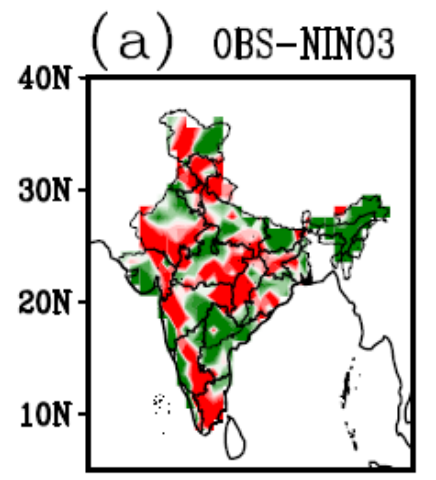

(d) MARCH-NINO3

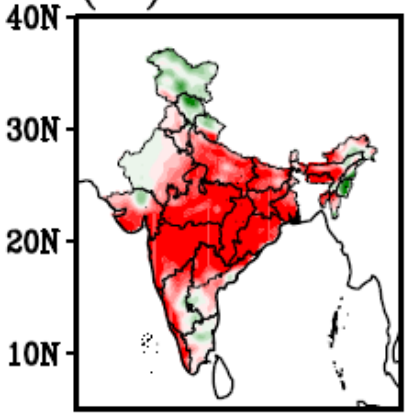

g) APRLL-NIN03
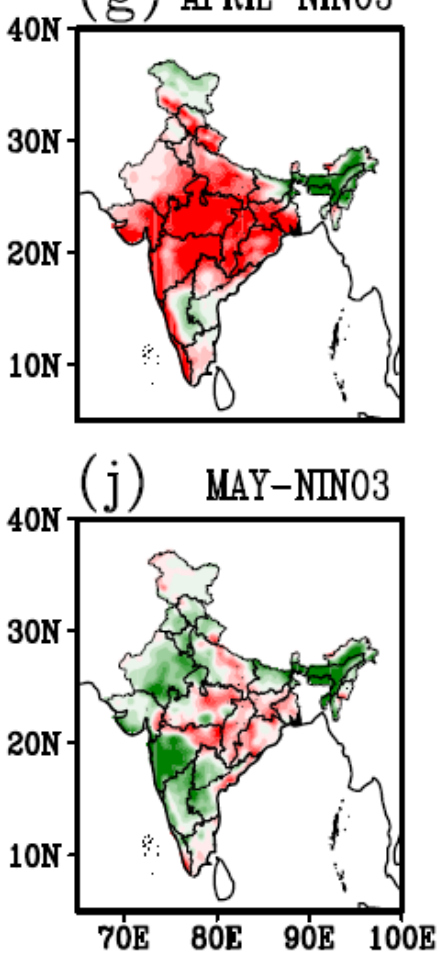
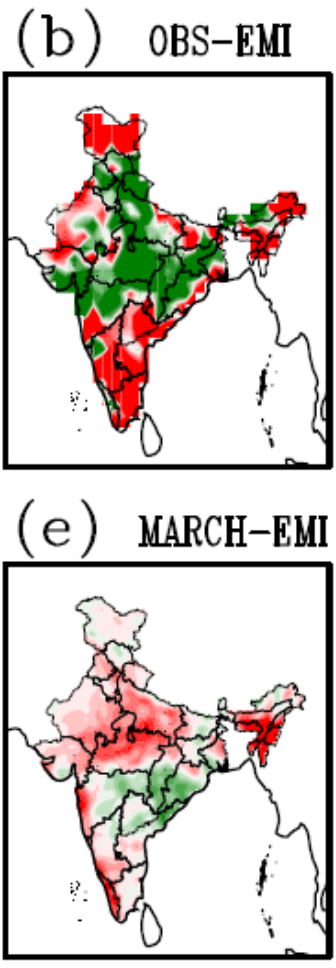

(h) APRIL-EMI

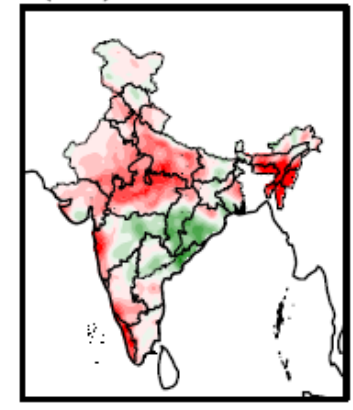

(k) MAY-EMI

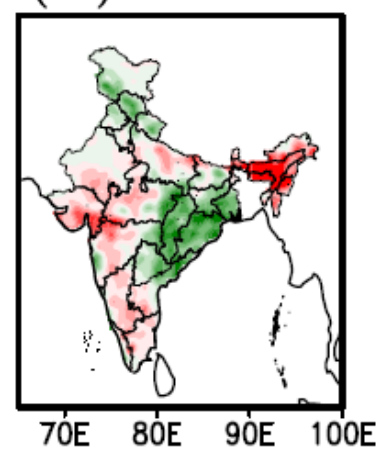

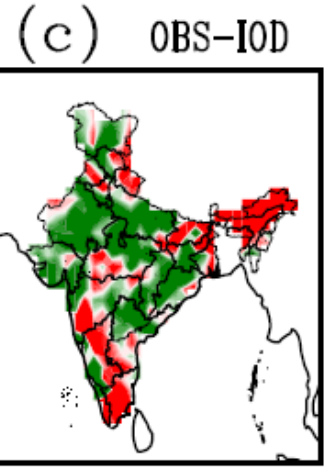

(f) MARCH-IOD

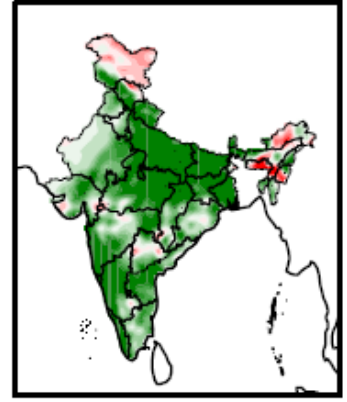

(i) APRIL-IOD

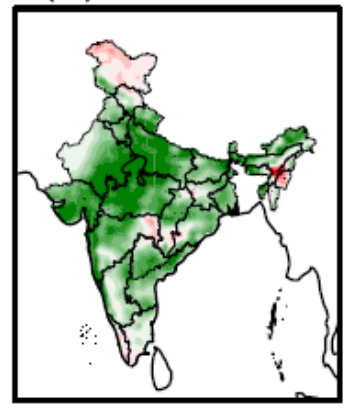

(1) MAY-IOD

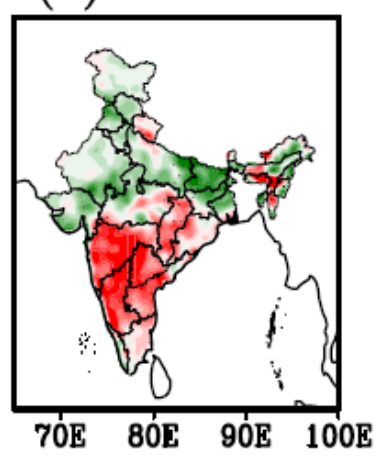

0.3

0.25

0.2

0.15

0.1<smiles>[18OH2]</smiles>

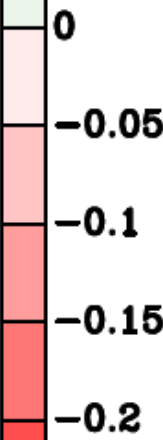

$-0.25$

Figure 2

Composite of anomalous rainfall during El Nino, El Nino Modoki and IOD events over India, during the period of 1981-2008, for the observed (a) to (c) and model simulations (d) to (I). Note: The designations employed and the presentation of the material on this map do not imply the expression of any opinion whatsoever on the part of Research Square concerning the legal status of any country, territory, city or 
area or of its authorities, or concerning the delimitation of its frontiers or boundaries. This map has been provided by the authors.
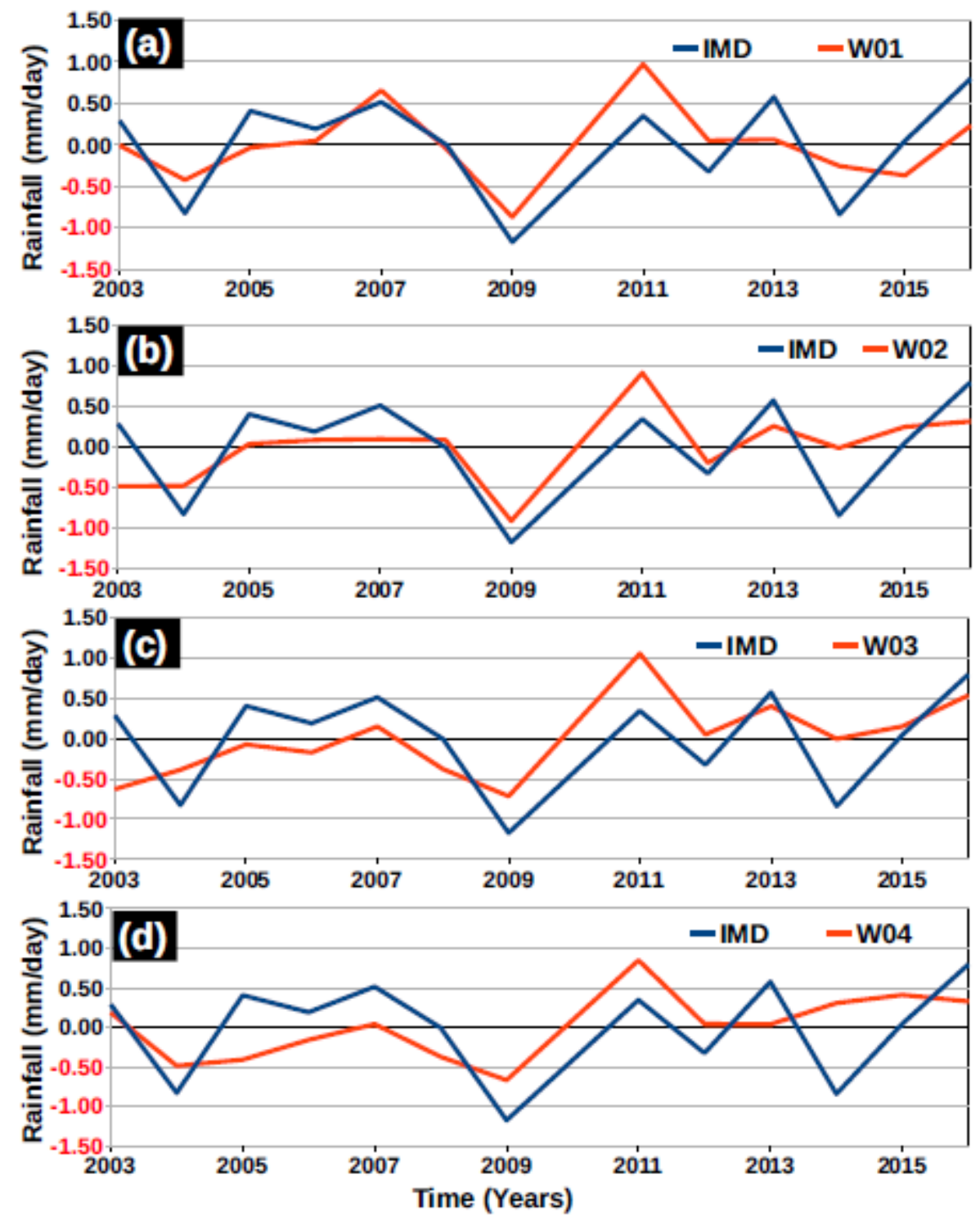

Figure 3

Observed(IMD) time series of area-averaged JJAS rainfall anomaly (blue), shown with those from the CFSv2 T126 extended range hindcast (mm/day; red) with different week leads (a) W01, (b) W02, (c) W03 and (d) W04 during 2003 to 2016 respectively. 

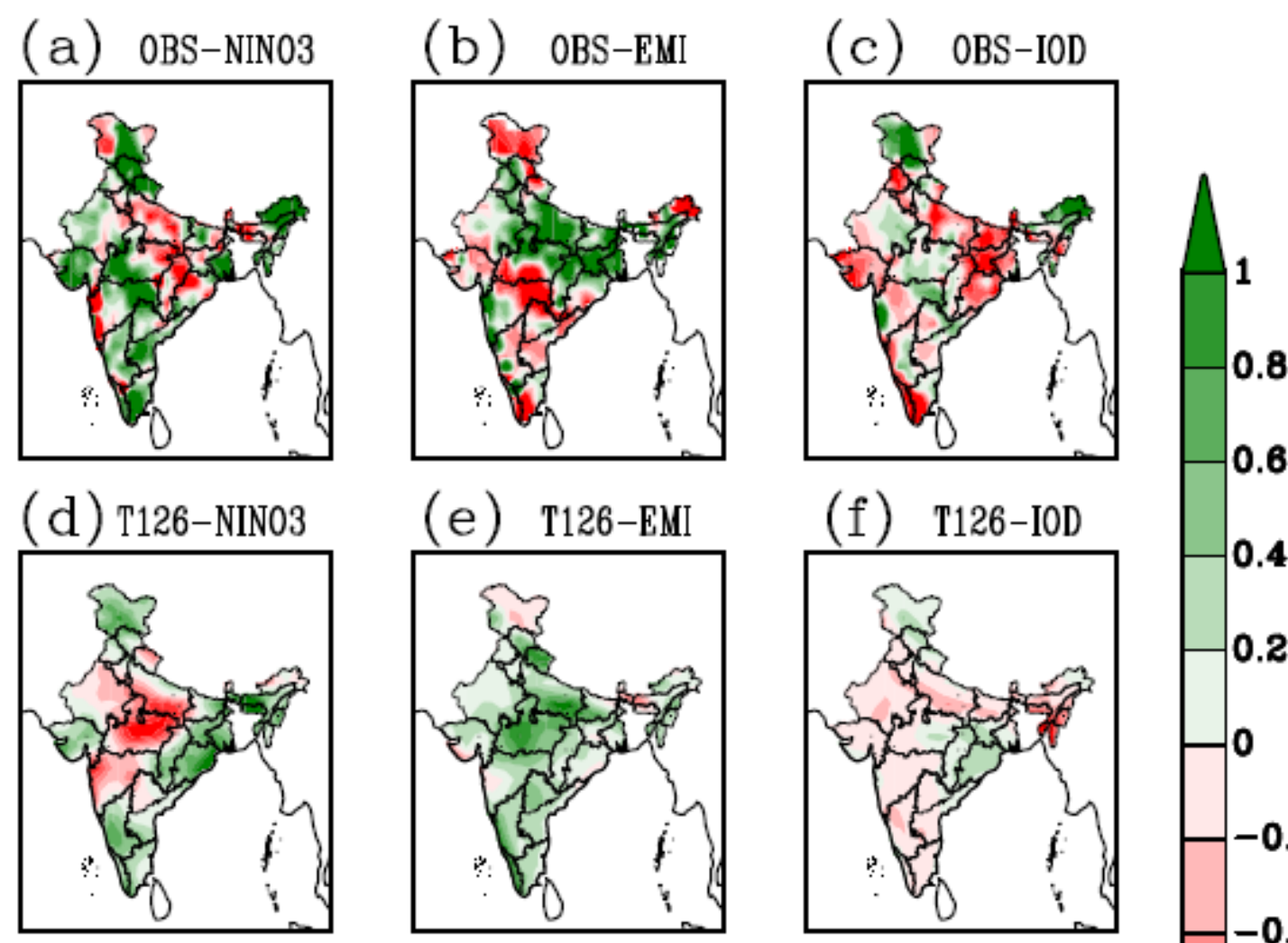

(g) T382-NIN03
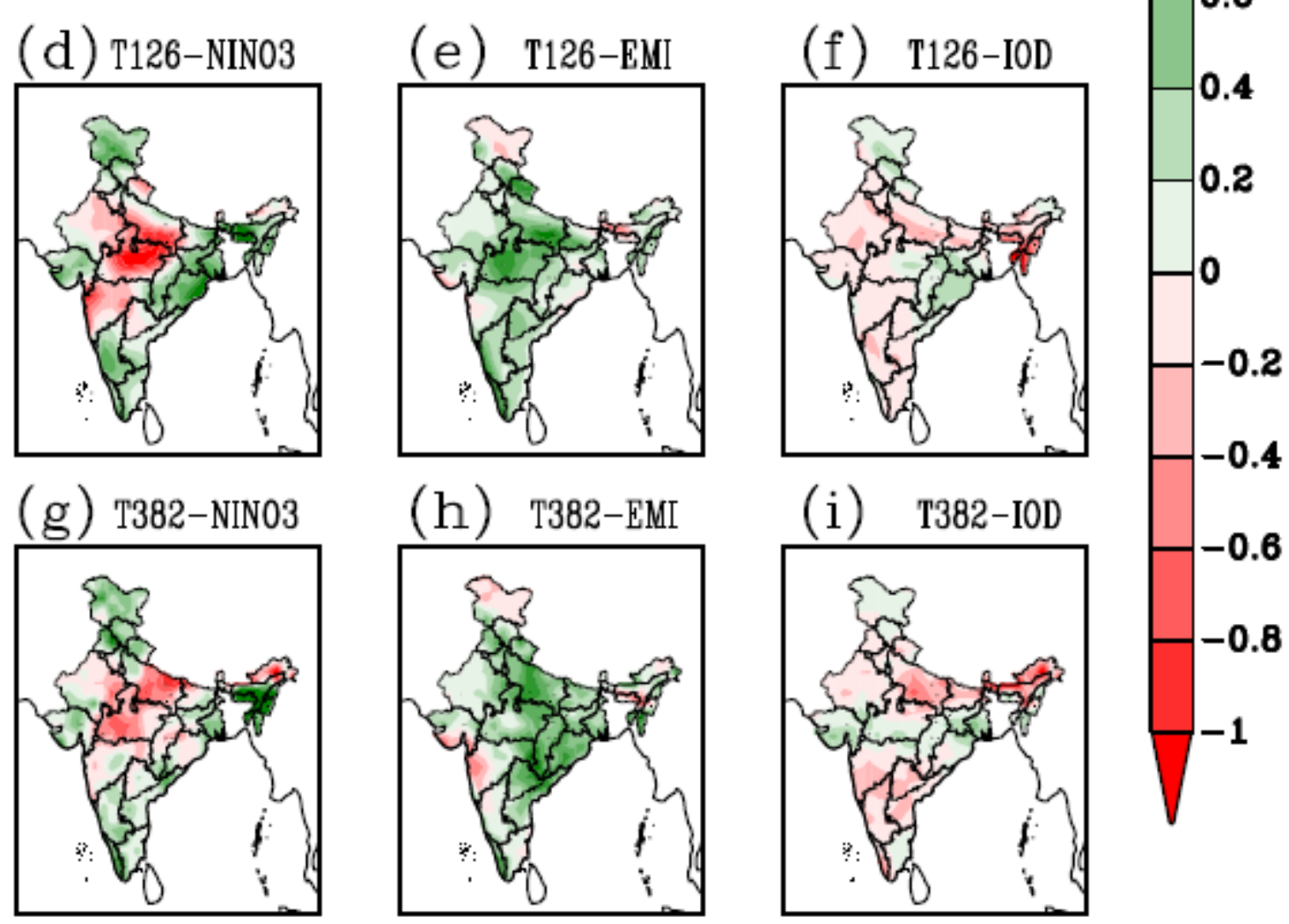

Figure 4

Composite of anomalous rainfall during El Nino (EI Nino Modoki and IOD) events over India, during the period of 2003-2015, for the observed (a) to (c) and extended range model simulations, T126 from (d) to (f) and T382 from (g) to (i). Note: The designations employed and the presentation of the material on this map do not imply the expression of any opinion whatsoever on the part of Research Square concerning the legal status of any country, territory, city or area or of its authorities, or concerning the delimitation of its frontiers or boundaries. This map has been provided by the authors. 